\title{
Upper Urinary Tract Calculi in Senegal: A Comparative Study between Open Surgery and Endoscopy, a Review of 89 Cases
}

\author{
R. Kane ${ }^{1}$, Y. Diallo², L. Niang3, A. Ndiaye ${ }^{1}$, M. Ndoye ${ }^{2}$, M. Jalloh ${ }^{2}$, M. Ogoubemy ${ }^{1}$, \\ S. M. Gueye 3 \\ ${ }^{1}$ Department of Urology, Principal Hospital, Dakar, Senegal \\ ${ }^{2}$ Department of Urology, Faculty of Health Sciences, University of Thies, Thies, Senegal \\ ${ }^{3}$ Department of Urology, Grand Yoff Hospital, Dakar University, Dakar, Senegal \\ Email: donekane2008@yahoo.fr
}

Received 27 May 2015; accepted 30 August 2015; published 2 September 2015

Copyright (C) 2015 by authors and Scientific Research Publishing Inc.

This work is licensed under the Creative Commons Attribution International License (CC BY). http://creativecommons.org/licenses/by/4.0/ (c) (i) Open Access

\section{Abstract}

Objective: The aim was to assess the place of endourologic intervention in our practice and compare it to open surgery in the management of upper urinary tract calculi in Senegal. Patients and Methods: This was a retrospective study conducted at both the Principal and Grand Yoff Hospitals of Dakar from January 2009 to December 2013 in which 89 patients with upper urinary tract calculi were mobilized. All patients with symptomatic upper urinary tract colic symptoms were included. Results: Eighty-nine were followed up during the study period, 63 men and 36 women (sex of ratio 1.2). The average age was 44 years with extremes 22 - 75 years. Forty two patients, including 28 men and 14 women (sex ratio $1: 2$ ) were treated with open surgery. The mean age was 42.75 years ( 4 - 75 years). The average duration of hospitalization after open surgery was 8 days (4 - 60 days). The mean stone size in open surgery was $23 \mathrm{~mm}(5 \mathrm{~mm}-45 \mathrm{~mm})$. Complications noted were: 2 cases of urinomas $(4.76 \%), 1$ case of lower back fistula $(2.38 \%), 1$ case of renal pelvis fistula (2.38\%) and 1 case $(2.38 \%)$ of infection. Forty seven patients including 35 men (55.6\%) and 12 women $(46.2 \%)$ were treated by endourology. The average length of hospital stay was 2 days $(2 \mathrm{~d}-3 \mathrm{~d})$. The average stone size treated by endourology was $13 \mathrm{~mm}(5 \mathrm{~mm}-40 \mathrm{~mm})$. No complications were observed in this group. The cost of open surgery was a third of that of endourology. Conclusion: Endoscopic surgery, as is observed from industrialized countries occupies a prominent place in the treatment of upper urinary tract calculi in Senegal; however, the only limiting factor encountered is the cost which remains out of reach for patients and burdening the

${ }^{*}$ Corresponding author.

How to cite this paper: Kane, R., Diallo, Y., Niang, L., Ndiaye, A., Ndoye, M., Jalloh, M., Ogoubemy, M. and Gueye, S.M. (2015) Upper Urinary Tract Calculi in Senegal: A Comparative Study between Open Surgery and Endoscopy, a Review of 89 Cases. Open Journal of Urology, 5, 142-146. http://dx.doi.org/10.4236/oju.2015.59022 
budgets of our hospitals with limited means.

Keywords

Upper Urinary Tract Calculi, Endourology, Open Surgery

\section{Introduction}

In recent years, we have seen the emergence of new technics such as extracorporeal lithotripsy and endourology in the management of upper urinary tract calculi [1]. In our context, despite the increasing use of new methods, open surgery is still the technic of choice. The aim of this study is to evaluate the place of endourology in our daily practice and compare it to open surgery in the management of upper urinary tract calculi in Senegal.

\section{Patients and Methods}

This was a retrospective study over a period of 5 years (January 2009-December 2013) at the Principal Hospital in Dakar and the General Hospital Grand Yoff. This study recruited 89 patients with symptomatic upper urinary tract calculi. Open surgical technics included, pyelolithotomy, nephrolithotomy, and uretolithotomy.

A preoperative Uroscan was requested for all patients to visualize locationand calculisize, in order to choose the most appropriate technique.

The following parameters were studied: age, sex, clinical signs, history, calculi size in mm, location of calculi, the side (right or left), the type of treatment, duration of hospitalization, urine bypass mode, ureteralprobe insertion time(s), complications and recurrence of calculi.

The data were processed using Epi-Info Version 3.5.1 2008 and the statistical calculations (ANOVA test, chi-square) and significance was evaluated at $\mathrm{p}<0.05$.

\section{Results}

During the study period, eighty nine patients were treated, forty-seven by endoscopy and forty two using open surgery. The average age was 44 years, ranging from 4 to 75 years. Standard deviation was \pm 15.3 .

The clinical manifestations were low back pain in 59 cases (66.29\%), renal colic in 28 cases (31.46\%), and hematuria (4 patients $4.5 \%$ ).

The technic distribution was nephrolithotomy for 2 patients (2.25\%), the pyelolithotomy (2 patients or 2.25\%), and shockwave lithotripsy for 2 patients.

The CT urography showed right calculi in 47 cases (52.81\%) and the left in 34 cases (38.20\%). The calculi were solitary in (91.01\%) and multiple in 8 cases (9\%).

Staghorn calculi represented 5 cases (5.6\%), calyceal in 12 cases (13.48\%), pyelicin 28 cases (31.46\%), lumber ureteral in 21 cases (23.59\%), iliac ureteral in 3 cases (3.3\%), pelvic ureteral in 9 cases (10.11\%) and lodged at the uretero-vesical junction in 11 cases (12.35\%) (Table 1 ).

The mean stone size was $16.88 \mathrm{~mm}$ with a range of $5 \mathrm{~mm}$ to $45 \mathrm{~mm}$.

Forty-two patients underwent open surgery.

The pyelolithotomy was performed in 22 patients (52.38\%). The average size calculations was $23 \mathrm{~mm}$ (12 $\mathrm{mm}-40 \mathrm{~mm}$ ). The average length of stay was 7 days (7 days - 60 days). The Complications were urinomas (2 cases) and pyelo fistula with pus.

The nephrolithotomy was performed in 7 patients (16.67\%) for 5 and 2 staghorn calculi calyx stones. The mean stone was $22.9 \mathrm{~mm}$ (12 mm - $40 \mathrm{~mm}$ ). The average hospital stay was 7 days ( $7 \mathrm{~d}-21 \mathrm{~d})$. One patient developed lumbosacral cutaneous fistula (14.28\%).

A patient of 38 years had a combination of the two approaches for the extraction of a $28 \mathrm{~mm}$ staghorn calculi. This patient had seven days of hospitalization and no complications were noted.

The ureterolithotomy was performed in 12 patients 9 lumber and 3 iliac pelvic calculi. The average size of stones was $11.12 \mathrm{~mm}$ (7 mm - $18 \mathrm{~mm}$ ). The average length of stay was 5 days (7 days - 4 days). No complications were noted (Table 2). 
All staghorn calculi were treated by surgery.

The treatment endourologic involved forty seven patients.

The flexible laser ureterorenoscopy was performed in 8 patients for kidney stones. The mean stone size was 6 $\mathrm{mm}(5-12 \mathrm{~mm})$.

The rigid ureterorenoscopy with laser lithotripsy was performed in 33 patients for ureteric stones. The average calculi size was $15 \mathrm{~mm}(6-20 \mathrm{~mm})$.

The probe basket was used directly in 6 patients with calculi lodged in theureterovesical junction. The mean stone size was $7 \mathrm{~mm}(6-13 \mathrm{~mm})$ (Table 3$)$.

No complications were noted in these 3 groups treated by endourology.

The average hospital stay in Endourology was 2 days (2 days - 3 days).

Finally, the cost of an intervention endourology amounted to 946.45 dollars while that of open surgery was 381.67 dollars for nephrolithotomy and renal pelvis lithotomy and 229 dollars for ureterolithotomy.

\section{Discussion}

In recent years, we have witnessed a sharp decrease of open surgery in the treatment of urolithiasis especially since the development of extracorporeal lithotripsy and endourology [1]. However, in the African setting, the role of open surgery remains dominant [2] [3].

Open surgery generally represents only $1 \%$ - $5 \%$ of surgical treatment of upper urinary tract calculi in Europe [4].

Table 1. Seat of calculation.

\begin{tabular}{ccc}
\hline Seat calculations & Workforce & Percentage (\%) \\
\hline Coralliform & 5 & 5.6 \\
Calyx & 12 & 13.8 \\
Pyelique & 28 & 31.46 \\
Lumbar urétéral & 21 & 23.59 \\
Ureteraliliac & 3 & 3.3 \\
Pelvicureteral & 9 & 10.11 \\
Uretero-bladder junction & 11 & 12.35 \\
\hline
\end{tabular}

Table 2. Summary of open surgery techniques, complications and size calculations.

\begin{tabular}{cccc}
\hline Techniques & Technicals & Complications & Size calculations (mm) \\
\hline Néphrolithotomy & 7 & Fistula(1), & 22.9 \\
Pyélolithotomy & 22 & Urinoma (2), fistula(1) & 23 \\
Néphro-pyéolithotomy & 1 & 28 \\
Urétérolithotomy & 12 & 11,12 \\
\hline
\end{tabular}

Table 3. Technical summary endoscopic.

\begin{tabular}{ccc}
\hline Technicals & Workforce & Size calculations (mm) \\
\hline Flexible urétéroscopy & 8 & 6 \\
Semi-rigiduréteroscopy & 33 & 7 \\
Direct extraction probe cart & 6 & 7 \\
\hline
\end{tabular}


According to the UAE [5] the indications for open surgery for upper urinary tract calculi are limited by complications of other techniques, calculi larger than $2 \mathrm{~cm}$, hard calculi (cystine), and complex anatomical abnormalities.

All staghorn calculi in our series (5.5\%) were treated by open surgery. They currently represent one of the indications of open surgery [5].

Calculi larger than $2 \mathrm{~cm}$ also represent an indication of open surgery as in our series, but percutaneous nephrolithotomy is the treatment of choice due the association with significant morbidity [5].

For the ureter, the open surgical technique described is open mini ureterotomy [6]. The indications are all proximal ureteral calculi but mostly those impacted or infected [7]. Morbidity is also high. This technic competes with laparoscopic ureterotomy [6] [7].

If open surgery is one of the techniques that provides the best stone-free state, it is also the most morbidity creating technic. The classical complications are fistulae, strictures and urinary tract infection of surgical site [8]. Such was the case in our study where five cases developed complications (pyelocutaneous fistulas, urinoma two cases of infectious syndrome, lumbosacral cutaneous fistula) representing $11.9 \%$ of the forty-two open surgery patients.

Forty seven patients in our series benefited from the new technics in our practice.

Only eight patients in our series were able to benefit from flexible ureteroscopy. Several authors agree on the efficacy of flexible ureteroscopy laser lithotripsy which is a kidney stones treatment technic with $80 \%$ good results when calculi size $\leq 2 \mathrm{~cm}$ without any influence the location and density of the stones [8]-[11].

Rigid or semi-rigid ureteroscopy (50\% of patients), was used for twenty six of the patients, ureteral calculi averaging $15 \mathrm{~mm}$ in size were seen. It is a technique of choice in the management of distal ureter calculi [10] [11].

There were no complications in this group of patients and the length of hospital stay (2 days) was shorter than in open surgery (8 days).

The cost of these new technologies in our practice, constitute a limiting factor to their continual use. Endourology intervention (946 dollars), costs three times that of open surgery (381 dollars). The cost factor humpers the promotion and of these technics which are out of reach of the financial capacities of our patients and are a burden the budget of our hospitals with often limited resources.

\section{Conclusion}

These new technics are now part of our armamentarium, but their exploitation is hampered by the cost to our patients and hospitals often with limited budgets.

\section{References}

[1] Honeck, P., Gunnar, W.N., Kromback, P., Bach, T., et al. (2009) Does Open Stone Surgery still Play a Role in the Treatment of Urolithiasis? Data of a Primary Urolithiasis Center. Journal of Endourology, 23, 1209-1212. http://dx.doi.org/10.1089/end.2009.0027

[2] Kambou, T., Traoré, C.A., Zango, B., Bonkougou, B., Ouattara, T. and Sanou, A. (2005) The Upper Urinary Tract Calculi in the Center Sanou Souro Bobo Dioulasso (Burkina Faso). Clinical Epidemiological and Therapeutic Aspects about 110. J of Urolcas. Afr, 11, 55-60.

[3] Ouattara, Z., Effoe, A.D., Tembely, A., Sanogo, Z.Z., Yena, Z., Doumbia, D. and Ouattara, K. (2004) Etude of 72 Cases of Upper Urinary Tract Stones at the Urology Department of the Hospital Point G Medical.

[4] Buchhloz, N.N., Hichings, A. and Albanis, S. (2006) The (Soon Forgotten) Art of Open Stone Surgery: To the Train or Not to Train? Ann R Collsurg Engl, 88, 214-217. http://dx.doi.org/10.1308/003588406X95075

[5] Türk, C., Knoll, T., Petrik, A., Sarica, K., et al. (2010) The European Association of Urology (EAU) Guidelines on Urolithiasis, Panels Have Prepared. European Association of Urology, 7, 27-28.

[6] Sharma, M.D., Maharaj, D. and Naraynsingh, V. (2003) Open Mini-Acess Ureterolithotomy: The Treatment of Choice for the Stone Refractory Ureteric. BJU International, 92, 614-616. http://dx.doi.org/10.1046/j.1464-410X.2003.04438.x

[7] Soares, R.S., Romanelli, P., Sandoval, M.A., Salim, M.R., et al. (2005) Retroperitoneoscopiy for Treatment of Renal and Ureteral. International Braz Journal of Urol Stones, 31, 111-116.

[8] Lechevallier, E., Traxer, O. and Saussine, C. (2008) Open Surgery of the Upper Urinary Tract Stones. Progress in Uro- 
logy, 18, 952-954. http://dx.doi.org/10.1016/i.purol.2008.09.013

[9] Mudassar, H., Asher, P., Pener, B., et al. (2011) The Limits of flexible MarkCynk. Redifinnig Ureterorenoscopy. Journal of Endourology, 25, 45-49. http://dx.doi.org/10.1089/end.2010.0236

[10] Breda, A., Ogounyemi, O., Leppert, J.T. and Schulman, P.G. (2009) Flexible Ureteroscopy and Laser Lithotripsy for Multiple Unilateral Intrarenal Stones. European Urology, 55, 1190-1196. http://dx.doi.org/10.1016/j.eururo.2008.06.019

[11] Diamarco, D.S., Chow, G.K., Gettman, M.T. and Seguera, J.W. (2005) Ureteroscopic Treatment of Upper Urinary Tract Calculi. Minerva Urologica e Nefrologica, 57, 17-22. 